\title{
High dose-rate brachytherapy of prostate cancer utilising Iridium-192 after-loading technique: Technical and methodological aspects
}

\author{
M. EDGREN ${ }^{1}$, A.M.EKELUND ${ }^{2}$, P. ALBERTSSON² ${ }^{2}$ L.M. LUNDBERG ${ }^{2}$,

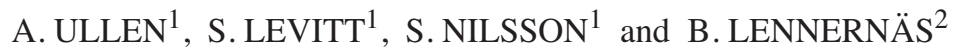 \\ ${ }^{1}$ Karolinska University Hospital and Institute, Stockholm; ${ }^{2}$ Sahlgrenska University Hospital, S-413 45 Gothenburg, Sweden
}

Received June 19, 2006; Accepted August 4, 2006

\begin{abstract}
The aim of this study was to focus on certain characteristic problems associated with Iridium-192 high dose-rate brachytherapy (Ir-192 HDR-BT) in combination with external beam radiation therapy (EBRT) in the treatment of patients with localised prostate cancer. Over a period of 16 years, $>2,000$ patients with prostate cancer have been treated in Sweden with a combination of two fractions of 10 Gy Ir-192 HDR-BT and 50 Gy of fractionated EBRT. Although this treatment is usually well tolerated, there are biological and technical factors to be considered before and during the treatment of the patient to avoid side effects or under-treatment of the target volume. Some of the problems facing the doctors are transducer stability, needle deviation, target definition, target motion, pubic arch interference, concomitant diseases and tolerance doses for different organs at risk. These problems are discussed and possible solutions are presented in this study.
\end{abstract}

\section{Introduction}

Prostate cancer is the most common malignancy afflicting Swedish men $(1,2)$. Annually, more than 9,000 new cases are diagnosed (3). Although health controls have been ardently discussed during recent years, no screening programmes have as yet been initiated in Scandinavia $(4,5)$. Radiotherapy and radical prostatectomy are generally regarded as the two chief modalities suitable for curative intent treatment (6-12). The results of treatment by these modalities are equivalent, but the acute and long-term side effects which develop after the definitive treatment of prostate cancer differ. The main side effects after surgery are impotence and

Correspondence to: Dr Bo Lennernäs, Department of Oncology, Sahlgrenska University Hospital, S-413 45 Gothenburg, Sweden E-mail: bo.lennernas@telia.com

Key words: brachytherapy, high dose-rate, curative treatment, prostate cancer, problems incontinence, while proctitis, colitis and cystitis are seen after radiotherapy (13).

The advantage of brachytherapy (BT) is the short irradiation range. This minimises the dose to organs at risk in the neighbourhood of the target, even though therapy requires that the irradiation source is placed inside or very near the target.

Prostate BT was first reported by Pasteau in 1911 (14). The complication rate was high, probably due to the application of the source through the urethra. In the years that followed, the treatment of prostate cancer has focused on radical prostatectomy and external beam radiation therapy (EBRT). However, two different techniques for obtaining a more homogeneous dose distribution in the prostate, which reduce the frequency of side effects, were reported by Flocks in 1964 (15), by Carlton (16) and by Whitmore et al in 1972 (17). These techniques utilized permanent implants of low doserate (LDR) Gold-198 and Iodine-125 isotopes, respectively. These reports resulted in a renaissance for prostate BT. In 1977, Court and Chassangne (18) began treating prostate cancer with after-loading techniques, and since then several reports have been published $(13,14,19-28)$. Although the data presented were encouraging, no randomised study has been published, and there are criticisms concerning some of the BT treatment studies $(29,30)$. Randomised clinical trials are planned by national groups (31), and in Sweden a randomised study in which patients with localised prostate cancer were treated with either surgery or BT in combination with EBRT was recently closed (unpublished data).

Over the past 16 years $>2,000$ patients in Sweden have been treated with a combination of two fractions of $10 \mathrm{~Gy}$ Ir-192 HDR-BT and 50 Gy fractionated EBRT. During this time, several technical problems were observed. In this study, possible solutions to these problems are suggested. Unfortunately, one cannot completely depend on literature for determining results of BT since frequently a distinction has not been made between LDR and HDR techniques. However, some of the problems related to trans-perineal implants are common to both approaches.

\section{Materials and methods}

EBRT is administered in two 2.5-week sessions (2 Gy/day, 5 days/week), with an interval of 2 weeks. The rest period 
begins and ends with the HDR-BT treatment. This technique has been described by Bertermann and Brix (32) and Lennernäs et al (EBRT) $(8,26)$. The patients also receive 3-6 months of pre-treatment Flutamid (250 mg x 3/day) and Leuprorelin (3.75 mg x 1/month).

More than 2,000 patients are included in this study. Preoperative investigations consist of a trans-rectal ultrasound (TRUS), bone scanning and blood tests which includes a prostate specific antigen (PSA). In cases of poorly differentiated tumours and when the PSA is $>10-20 \mathrm{ng} / \mathrm{ml}$ in well to moderately differentiated tumours, a lymph node dissection is always performed. Only patients with no lymph node or skeletal metastasis and stage T1-T3b (UICC 1992) are accepted for curative intent treatment. The maximum accepted pretreatment size of the prostate is $60 \mathrm{cc}$, but this has been omitted in recent years.

Dose planning is performed 1-2 weeks before the first BT utilizing TRUS. During planning and treatment the patients are placed in a dorsal lithotomy position. Usually a catheter is placed in the urethra to assist in planning the treatment and to avoid over treating the urethra. No anaesthesia is used during planning. The ultrasound image of the prostate is divided into $5 \mathrm{~mm}$ thick slices using a stepsection planemetry mechanism (Fig. 1). Using the images the boundaries of the prostate gland and the rectum are outlined and information essential for dose planning is noted. The geometrical information is transferred to the computerised dose planning system, which calculates the planned coordinates of the needles, and the planned dose delivered by each source position in the needles. After 2003, pre-planning has not been performed in Gothenburg, but instead, planning is performed before and on-line prior to each treatment.

The target is defined as the prostate gland plus a $2-3 \mathrm{~mm}$ margin. The dose to the wall of rectum is limited to $6 \mathrm{~Gy}$ on a line of $2-3 \mathrm{~cm}$ through the rectum. The urethral volume should not be $>8 \mathrm{~Gy}$. When possible, a 5 Gy-boost (total $15 \mathrm{~Gy}$ ) is given to a visible tumour in one lobe of the gland and 8 Gy to the other lobe.

Prior to the treatment, the patient is anaesthetised routinely with local spinal anaesthesia. The patient also received prophylactic antibiotic treatment before BT. Approximately 5-18 needles, which guide the irradiation source, are then inserted through a matrix in co-ordinates according to the dose plan. The positions of the needles are confirmed by TRUS before treatment. The urethra is localized by the use of a catheter, which is placed in the urethra.

\section{Results}

Generally, the acute morbidity of this treatment is acceptable and comparable to definitive EBRT (>70 Gy) except for temporary nocturia, which can be as frequent as 6-8 times per night. No operative death occurred, nor does the frequency of late side effects differ from those of external beam irradiation $(13,19,33)$.

Problems associated with the technique. It is well known that there is a marked learning curve associated with the use of BT, either LDR or HDR (34). The following section will address some of these and suggest possible solutions.

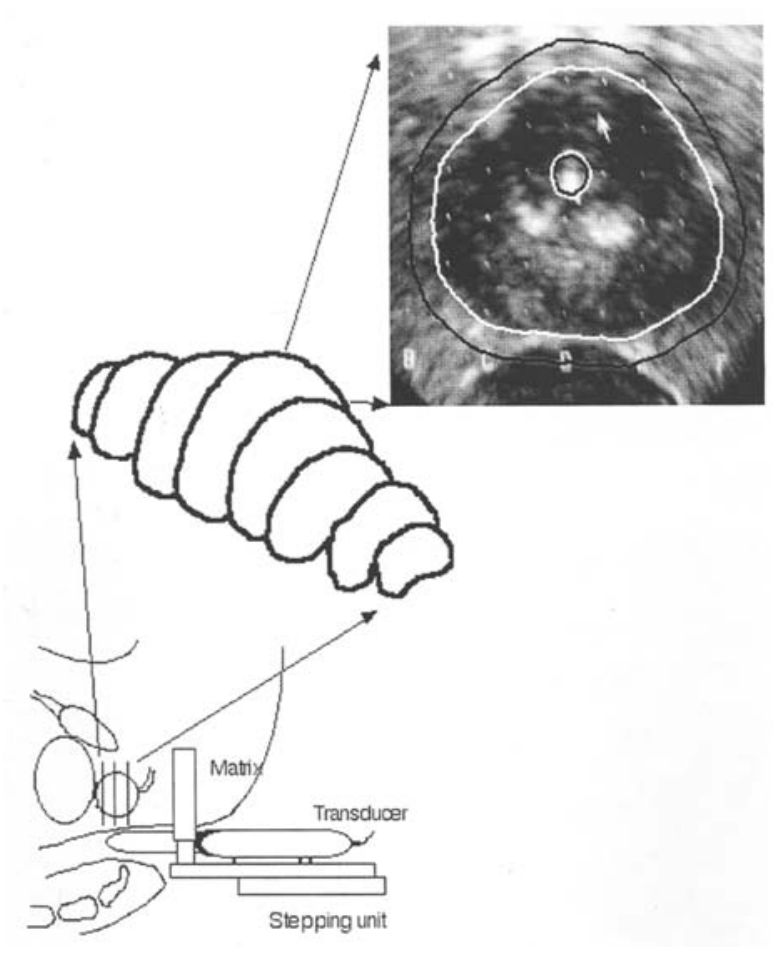

Figure 1. A close view of the transducer, the matrix and the stepping unit. The patient is in treatment position with legs up and the transducer in the rectum. The needles are inserted in the perineum. The prostate is divided in $5 \mathrm{~mm}$ thick slices.

Stability of the ultra-sound (US) transducer mechanics. The distance between the US transducer and the needle matrix must be constant throughout the treatment in order to reproduce the positions of the transducer, the needles and the tumour. When using a rectal ultrasound transducer the matrix is connected directly to a point very near the transducer's tip. Consequently, movement of the transducer would influence the matrix thus producing a more firm relationship between the needle position and transducer. When using rectal ultrasound transducer the matrix is connected directly to a point near the transducer's tip, which produces a firm connection between the needle position and the transducer.

When using non-rectal transducers the matrix is fitted to the stepping device (Fig. 1), and mechanical instability can occur. Thus, it is important to control the maximum possible movement of the stepping device and to develop mechanical solutions, which lock the transducer in a fixed position.

Deviation of needles. Deviation of needles is a common problem (35). Under-dosage of the target can be a serious problem, if the positioning of the needles is inaccurate. This can be calculated by the dose volume inhomogenity corrected biological effective dose (DVIC-BED) formula, which has revealed that even small deviations and under-dosage of the target (5-10\%) can have a serious impact on local control of the tumour (36). One advantage of the after-loading technique, in contrast to the permanent implant technique, is the possibility of repositioning the needles or even recalculating the entire dose plan before the start of treatment. However, it is not always possible to compensate for every small deviation of the needles, and it is therefore essential 


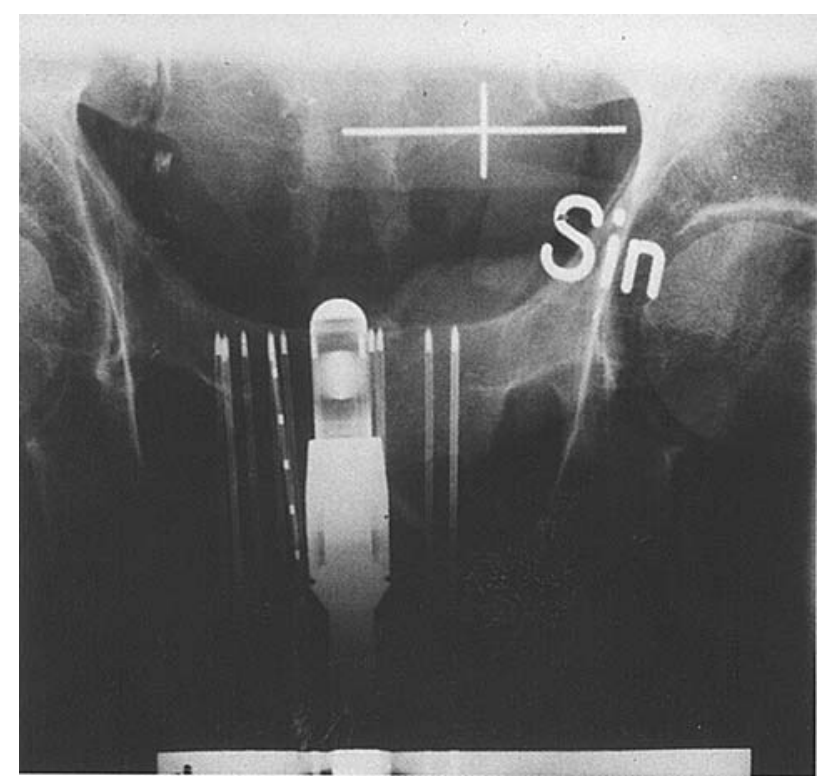

Figure 2. The effect of a lanced needle is shown. By using lanced needles, the needles can be forced into the correct position, and will deviate in the prostate gland due to the cut of the needle.

that the physician is aware of the allowable deviation of a needle. The operator must always consider the location of the tumour, the weight and number of the source positions in the needle and the planned margin in the vicinity of the needle when making final decisions.

The use of lanced needles. Fig. 2 shows one needle deviating by several millimetres in the prostate. This was done on purpose, since it was not possible during this treatment to insert the needle in the planned co-ordinates of the matrix. By using a lanced needle, the needle can be deliberately forced to deviate in a particular direction. In Fig. 2 the needle is visualised by a marker on the X-ray image. Since the position of the needle is determined on the bladder side of the prostate at the tips of the needles, the deviation of the needle and consequently the under-dosage in the target is minimised.

Since it is almost impossible to deviate from a needle channel with standard needles, the lanced needle can also be used for pre-penetration. These needles however have their limitations. In a prostate gland with much calcification, it is sometimes difficult to insert the needles in the desired position. In these situations, fast on-line dose planning systems for re-planning with the actual positions of the needles are necessary.

\section{Problems associated with anatomy}

Shape of the prostate. The shape of the prostate may change between dose planning and treatment. Generally the size is smaller and can be more pronounced anteriorly. Even when the time between dose planning and treatment is reduced to one day this can be observed. The reason is unclear. It is thought that the anaesthetic procedure may to some extent influence the size of the prostate directly or indirectly by lowering the tension in the pelvic region. However, with the introduction of on-line planning this problem is eliminated.
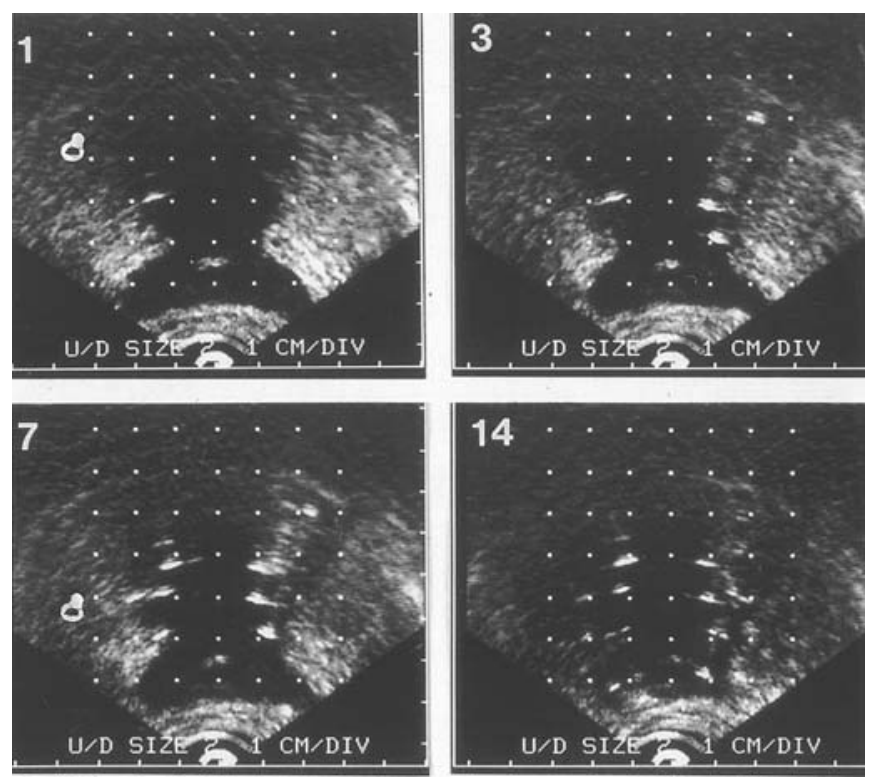

Figure 3. Changes in the shape of the prostate with $1,3,7$ and 14 needles inserted. The shape of the prostate is changed in the slice, due to the movement of the gland.

In the future, better ultrasound systems, or magnetic resonance imaging (37), may reduce the uncertainty of different target definitions, in the meantime we must be attentive to the problems of target definition.

Motion of the prostate. In Fig. 3, video printer images were taken while needles number 1, 3, 7 and 14 were inserted into the prostate during treatment. Remarkable contour changes of the prostate gland can be seen. However, the prostate gland may show a very steep margin in the cranial part and a small movement in the caudo-cranial direction can produce a large variation in the contour of the gland in the ultrasound image.

In these situations, transducers with the capacity to produce sagittal projections, such as the B\&K 8551, can be most helpful. Other possible solutions are fixation of the prostate with dedicated needles (MD Tech, FL, USA) or by using a simple method of fixation described by Dattoli and Waller (38). The latter method uses two needles which are inserted trans-perineally and obliquely into the prostate.

Another ultrasound phenomenon is seen in Fig. 4 where a needle is inserted in the upper part of the gland (see arrow). When a second needle is inserted below the first needle, the echo of the first needle will sometimes disappear due to the strong reflection of the second needle. Thus, it is important to remember that needles in the more dorsal part of the gland can hide needles along a straight line from the transducer. As a consequence of this phenomenon, needles near the transducer should be inserted last.

The visualisation of the needles can be problematic and the authors' experience is that changing the frequency of the ultrasound may improve the ability to detect a specific needle. Thus, multi-frequency ultrasound transducers can be helpful in needle detection and also in delineation of the prostate gland. 


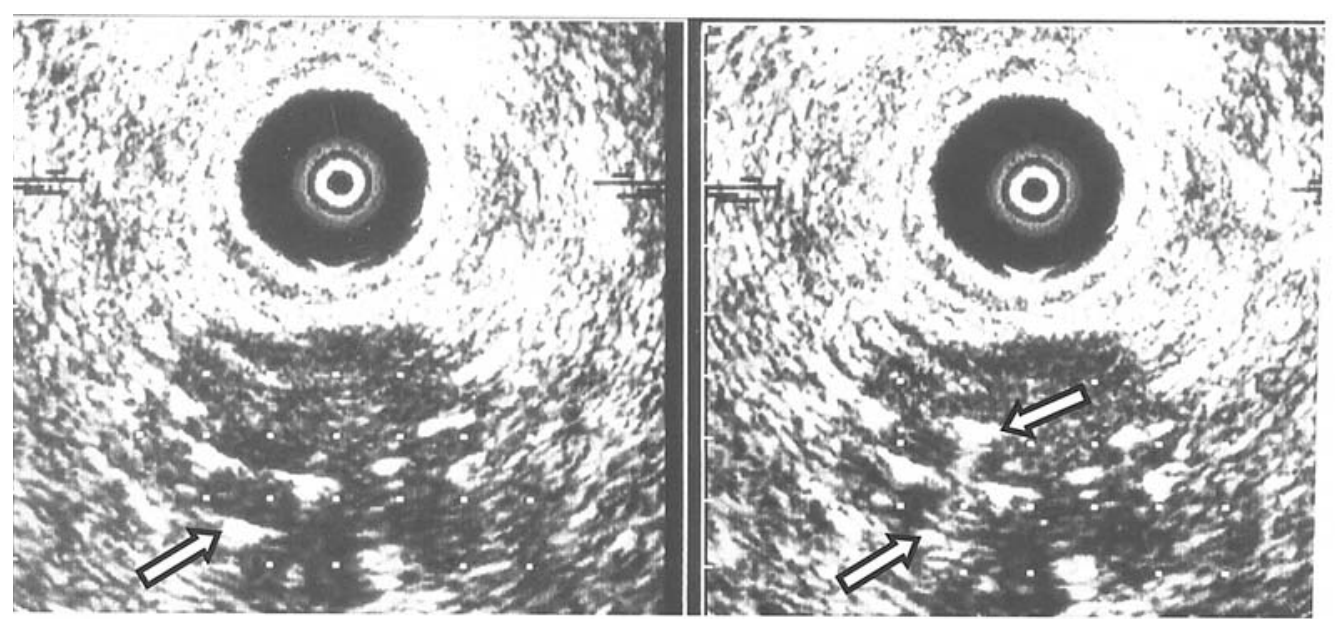

Figure 4. A needle is inserted in the upper part of the gland and since it lies in a straight line with the second needle (arrow) and the transducer, it will disappear due to the strong reflection of the lower needle.

Prostate size and the pubic arch. Restricting the size of the prostate gland is recommended. Patients with a prostate volume of $<40 \mathrm{cc}$ seldom show pubic arch interference problems, whereas in patients with prostate volumes $>60 \mathrm{cc}$, treatment can be difficult (39). However, if the gland can be covered by at least 8 Gy of HDR-BT combined treatment might still be a good choice. The greatest technical problem in the treatment of large glands is the insertion of needles into the upper lateral parts of the gland, due to pubic arch interference with positioning of the needles. Concerning small prostate volume, Loblaw et al have investigated the feasibility of BT with permanent implants, and found that a small volume per se was not a contraindication for BT (40).

Pubic arch interference can be avoided, to some extent, by rotation of the pelvis mechanically. This can be achieved by utilizing an extended lithotomy position. This procedure creates more space between the prostate and the pubic arch. However, some glands are located more anteriorly in the pelvis and are difficult to cover with a sufficient HDR-BT dose. The same problem is present in patients with a narrow pelvis or a large prostate. Tincher et al have stressed the importance of both rotating the pelvis and using an upward direction of the needles during treatment in order to avoid the pubic arch (41).

Online planning can also solve some of these problems. Kalapurakal et al have suggested that the CT scanning performed as a basis for EBRT planning or pre-implant, can be used for pubic arch interference analysis (42).

It has also been shown that neo-adjuvant hormonal therapy (NHT) may reduce the size of the prostate by $30-50 \%$ $(43,44)$, although the impact on side effects or survival in BT is not clear $(45,46)$. One must also bear in mind that volume estimation of the prostate gland is not exact, and it has been suggested that differences up to $25 \%$ should be expected between different non-planimetric estimates $(47,48)$.

Potentially large individual differences have also been reported in other studies (48). The value of NHT for the outcome of the disease when using high dose radiation therapy has been questioned (49).

Variation in the volume of the prostate is a well known phenomenon during EBRT. Antolak et al (20) have noted variations of up to $3.5 \mathrm{cc}( \pm 1.6 \mathrm{cc})$ in the size of the prostate using repetitive $\mathrm{CT}$ scans during EBRT.

Narayana et al have reported that CT overestimates the volume of the prostate, thus, volume estimation based on CT scans is not recommended (50).

Another restriction is the presence of a lobus tertius of the prostate inside the bladder. These lobes can be difficult to treat with a sufficient dose during the treatment and should be accepted for treatment only after careful consideration. This stresses the importance of a pre-treatment assessment using a TRUS investigation for determining the volume, pubic arch and stage.

The BT equipment can also be used for implantation of gold fiducial markers (51). In cases where it is found that BT is not possible to perform with the patient positioned on the treatment table, it is feasible to implant gold markers and to convert the treatment to dose escalated EBRT. Concerning size and pubic arch interference a retrospective analysis in Gothenburg, of cases converted to gold marker technique shows that factors other than the size of the prostate are also important for pubic arch interference.

The urethra. The radiation dose to the urethra is a major concern. The urethra is a radiation sensitive organ, and severe side effects were reported in early BT treatments. Stricture development is a well-known problem $(13,19)$. Dinges and collaborators reported on doses producing late 3-4 grade side effects. Five percent risk for severe side effects was noted at $91 \mathrm{~Gy}$, and $50 \%$ risk at $160 \mathrm{~Gy}$ converted into 2 Gy fractions (23). Thus it is important to outline the urethra and at the same time, there is a problem in visualising the position of the urethra in the planning position. One solution is to mark the urethra with a catheter. It is also possible to inject air containing gel or contrast media for marking the urethra (52).

The position of urethra must be outlined before dose planning, in order to avoid excessive doses to the urethra. Waterman and Dicker have reported that the geometric centre of the prostate is an acceptable surrogate for the location of the urethra (53). Although this might be true for a majority of patients, the experience obtained in this study revealed that many patients have significant deviations of the urethra. In a 

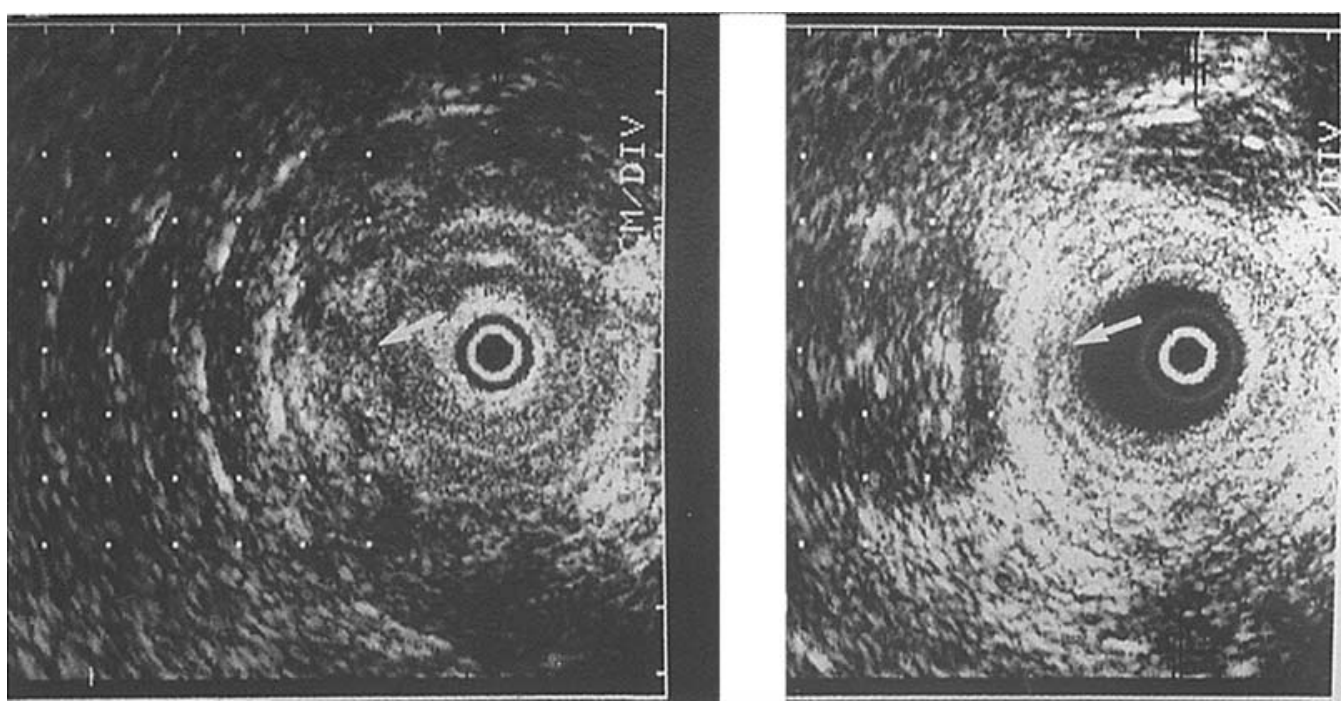

Figure 5. Change of position of the rectum wall after deflating the transducer probe (arrow at some geometric point). This anatomical change is also obvious if the transducer is removed before treatment, and this will obstruct investigations of radiobiogical relationships between the planned dose-distribution and a certain side effect.

study by Stromberg et al, flexible cystoscopy was performed during treatment to ensure that no needles were inserted into the urethra or bladder neck (22).

Definition of the rectal wall and the prostate. Definition of the rectal wall as well as the prostate gland has been the subject of debate over the years. Since the dose to the rectum is defined on a transverse line of $2-3 \mathrm{~cm}$ (or later as a reference point in the rectum wall), it is important to outline the margin of the rectum correctly. Most often the distance between the rectum and the prostate is greater during treatment than during planning, possibly due to the anaesthetic procedure, which increases the safety of the treatment. If a water balloon is used to expand the rectum during planning and during insertion of the needles, the balloon should be collapsed during treatment, in order to increase the distance between the rectum and the prostate (Fig. 5).

One major problem is how to define the rectum wall. There are at least four answers to this question. One is to outline the endothelium of the rectum, or the inner portion of the muscle layer. Another approach is to outline the middle portion of the muscle layer of the rectal wall or the muscle layer outside the mucosa. This clearly illustrates the need for a prompt standardised approach to solve this issue. These variations of target definition are unsatisfactory and are subject for revision in Sweden.

Concomitant diseases, contraindications and follow-up. There are no additional contraindications when comparing BT to EBRT except for those associated with the local spinal anaesthesia and the prophylactic antibiotics given during BT treatment. A study by Dicker et al has questioned the use of prophylactic antibiotics in standard trans-perineal BT treatment (54).

Inflammatory bowel disease (IBD) such as Crohn's disease and ulcerative colitis are generally contraindications for pelvic irradiation. However, Grann and Wallner have reported on prostate BT using I-125 in patients with IBD as a safe combination, although the information is limited (55). Dinges et al reported that 2 out of the 3 patients with severe side effects had IBD (23). These patients developed a rectourethral fistula after biopsies from the anterior wall of the rectum. A history of prostatitis is also a contraindication for BT. However, Aggarwal et al have reported that BT may be recommended even with a previous history of prostatitis (56). Urethral stents placed in the prostatic part of the urethra do not seem to be a contraindication for BT (40).

Follow-up schedules are no different for BT patients than for EBRT patients (57). However, it is important to remember that PSA bounce is common following BT, and a temporary PSA rise can be as high as $20 \mathrm{ng} / \mathrm{ml}$ post therapy. Critz et al (57) observed a PSA bounce in $35 \%$ of the BT patients with a median time to PSA bounce of 18 months, and a median PSA of $0.7 \mathrm{ng} / \mathrm{ml}$. These authors also found no relationship between the occurrence or magnitude of the PSA bounce and recurrence of the disease (57). However, Hanlon et al found that PSA bounce was associated with a decrease in biochemical control rates (58). Nickers et al have presented PSA kinetics after EBRT (59). The graphs in their study can be useful in evaluation of treatment or of a specific patient.

Radiobiology. Recently the $\alpha / \beta$ ratio for the prostate has been the subject of discussion by Brenner et al (60), and Fowler et al $(61,62)$, and the ratio suggested was as low as 1.5 . There are indications that prostate cancer behaves more like late reacting tissue rather than acute reacting tissue with little or no proliferation occurring during a 6 to 8 -week treatment course, and it has also shown that radiotherapy of prostate cancer is less sensitive to treatment time (63). A lower $\alpha / \beta$ ratio will result in a greater radiobiological effect per radiation dose. This means that BT schedules which were designed to be equal to $70 \mathrm{~Gy}$ in $2 \mathrm{~Gy}$ fractions should, in reality, be considered as dose escalated treatments. However, there are no studies on survival comparing different $\alpha / \beta$ ratios, and one must be cautious in using or designing new schedules based on an assumed low $\alpha / \beta$ ratio. 
King published an overview on radiobiological models for both LDR- and HDR-BT (24). This can also be useful in the evaluation of these two modalities. In this review, the advantage of high dose per fraction and the possible advantage of treating prostate cancer with high doses and HDR-BT were outlined.

\section{Discussion}

The combination of HDR-BT and EBRT is increasingly used as a curative treatment option for localised prostate cancer. Hanks et al have presented dose response curves for prostate cancer based on pre-treatment PSA (7). From these data, it can be seen that a dose of $80-85$ Gy is needed to reach biochemical, PSA, no evidence of disease (bNED) in approximately $90 \%$ of the patients. The corresponding dose in 2 Gy fractions of the combined treatment used in Sweden is 96 Gy (assumed $\alpha / \beta$ ratio $=4)$. However, as previously mentioned, this dose may be considerably lower, and it is well known that a small volume of under-dosage can have a considerable effect on the tumour control probability $(36,64)$. Thus, the critical issue in HDR-BT of the prostate is a close match between the planned needle positions and the actual achieved positions during treatment.

This treatment combination of HDR-BT and EBRT is also advantageous if displacement errors of the EBRT are considered. Since the target receives a high dose, the treatment is located in the upper portion of the dose response curve (7). This means that the combined treatment is more resistant to displacement errors than EBRT only, which is located in the steep section of the dose response curve (70-80 Gy). It is unlikely that a higher proportion of patients will be cured by increasing the dose above $96 \mathrm{~Gy}$, but this will certainly decrease the safety margin of the treatment. However, as pointed out, one must be aware of the limitations in both radiobiological calculations and parameter determinations. Furthermore, as pointed out by Martinez et al, it is not certain that neoadjuvant hormone therapy will increase survival or local control in these high dose treatments (49).

Although the treatment has relatively few side effects, it does have side effects and severe complications, primarily involving the rectum, such as rectal bleeding and chronic proctitis (13). Further development of this treatment is necessary to protect the organs at risk, without reducing the dose to the target. These include better target or anatomical structure definitions, on-line dose planning and a better understanding of the dose volume relationships of the organs at risk (rectum and the urinary bladder) (39).

In an analysis from Gothenburg (unpublished data), the dose to the urethra and rectum was retrospectively estimated and compared to side effects in patient records. The total frequency of severe urinary complications 1988-1995 was $17 \%$ (11\% strictures) compared to $5 \%$ during 1995-1998. The number of severe GI complications was $2 \%$ versus $0 \%$, respectively. The dose to the rectum was similar between the two periods, but the dose to the urethra was higher 1988-1995. The reason for the difference could be longer follow-up, but also due to the 'learning curve', better equipment and better dose distributions. The introduction of amifostine (Ethyol ${ }^{\circledR}$ ) might also be beneficial in some patients (65).
In summary, the most important organs at risk are the rectum, urethra, urinary bladder, neurovascular bundle (NVB), hip, gut and skin. Tolerance doses for the first three are well known and the last three are seldom a problem. However, it is clear that the short range of HDR-BT decreases the dose to the surrounding organs at risk. The tolerance dose to the NVB still remains unknown.

\section{Acknowledgements}

This study was supported by grants from the King Gustav V's Jubilee Clinic Cancer Research Foundation, Gothenburg, Swedish Cancer Society, the Cancer Society and Jubilee Fund, Stockholm, Sweden.

\section{References}

1. A prospective survey of radiotherapy in Sweden. Acta Oncol 35 (Suppl 6): 47-56, 1996.

2. Cancer trends in Sweden until 2010. Acta Oncol 35 (Suppl 6): 37-45, 1996.

3. Socialstyrelsen: Cancera Incidence in Sweden. http://wwwsosse/ sos/statistihtm 2003.

4. Andersson L: Mass screening for prostate cancer. Acta Oncol 37: 513-514, 1998.

5. Albertsen P: Is screening for prostate cancer with prostate specific antigen an appropriate public health measure? Acta Oncol 44: 255-264, 2005

6. Bagshaw MA: Potential for radiotherapy alone in prostatic cancer. Cancer 55: 2079-2085, 1985.

7. Hanks GE, Hanlon AL, Schultheiss TE, Pinover WH, Movsas B, Epstein BE and Hunt MA: Dose escalation with 3D conformal treatment: five year outcomes, treatment optimization, and future directions. Int J Radiat Oncol Biol Phys 41: 501-510, 1998.

8. Lennernas B, Rikner G, Letocha $H$ and Nilsson S: External beam radiotherapy of localized prostatic adenocarcinoma. Evaluation of conformal therapy, field number and target margins. Acta Oncol 34: 953-958, 1995.

9. Hanks GE: Strategies for improving the outcome of patients with poor prognosis prostate cancers. Acta Oncol 37: 3-9, 1998.

10. Hanks GE: Progress in 3D conformal radiation treatment of prostate cancer. Acta Oncol 38 (Suppl 13): 69-74, 1999.

11. Nilsson S, Norlen BJ and Widmark A: A systematic overview of radiation therapy effects in prostate cancer. Acta Oncol 43: 316-381, 2004.

12. Glimelius B and Steineck G: Low evidence of radiation therapy in prostate cancer-a plea for intensified scientific activity. Acta Oncol 43: 311-315, 2004.

13. Wahlgren T, Nilsson S, Ryberg M, Lennernas B and Brandberg Y: Combined curative radiotherapy including HDR brachytherapy and androgen deprivation in localized prostate canccer: a prospective assessment of acute and late treatment toxicity. Acta Oncol 44: 633-643, 2005.

14. Porter AT and Forman JD: Prostate brachytherapy: an overview. Cancer 71: 953-958, 1993.

15. Flocks RH: Interstitial irradiation therapy with a solution of Au198 as part of combinationtherapy for prostatic carcinoma. J Nucl Med 10: 691-705, 1964.

16. Carlton CE and Scardino PT: Long-term results after combined radioactive gold-198 seed implantation and external beam radiotherapy for localised prostatic cancer. In: BT of Prostatic Cancer Nucleotron. Bruggmoser G, Sommerkamp H and Mould RF (eds). Veenendaal, 1991.

17. Whitmore WF Jr, Hilaris B and Grabstald H: Retropubic implantation to iodine 125 in the treatment of prostatic cancer. J Urol 108: 918-920, 1972.

18. Court B and Chassagne D: Interstitial radiation therapy of cancer of the prostate using Iridium 192 wires. Cancer Treat Rep 61: 329-330, 1977.

19. Astrom L, Pedersen D, Mercke C, Holmang S and Johansson KA: Long-term outcome of high dose rate brachytherapy in radiotherapy of localised prostate cancer. Radiother Oncol 74: 157-161, 2005 . 
20. Antolak JA, Rosen II, Childress CH, Zagars GK and Pollack A: Prostate target volume variations during a course of radiotherapy. Int J Radiat Oncol Biol Phys 42: 661-672, 1998.

21. Prestidge BR: Radioisotopic implantation for carcinoma of the prostate: does it work better than it used to? Semin Radiat Oncol 8: 124-131, 1998.

22. Stromberg J, Martinez A, Gonzalez J, et al: Ultrasound-guided high dose rate conformal brachytherapy boost in prostate cancer: treatment description and preliminary results of a phase I/II clinical trial. Int J Radiat Oncol Biol Phys 33: 161-171, 1995.

23. Dinges S, Deger S, Koswig S, Boehmer D, Schnorr D, Wiegel T, Loening SA, Dietel M, Hinkelbein W and Budach V: High dose rate interstitial with external beam irradiation for localized prostate cancer - results of a prospective trial. Radiother Oncol 48: 197-202, 1998.

24. King C: LDR vs HDR brachytherapy for localized prostate cancer: the view from radiobiological models. Brachytherapy 4 : 219-226, 2002.

25. Ash D, Bottomley DM and Carey BM: Prostate brachytherapy. Prostate Cancer Prostatic Dis 1: 185-188, 1998.

26. Lennernas B, Holmang S and Hedelin H: High-dose rate brachytherapy of prostatic adenocarcinoma in combination with external beam radiotherapy a long-term follow-up of the first 50 patients at one center. Strahlenther Onkol 178: 537-541, 2002.

27. Vicini F, Vargas C, Gustafson G, Edmundson G and Martinez A: High dose rate brachytherapy in the treatment of prostate cancer. World J Urol 21: 220-228, 2003.

28. Kovacs G, Galalae R, Loch T, Bertermann H, Kohr P, Schneider R and Kimming B: Prostate preservation by combined external beam and HDR brachytherapy in nodal negative prostate cancer. Strahlenther Onkol 175 (Suppl 2): 87-88, 1999.

29. Wirth MP and Hakenberg OW: Brachytherapy for prostate cancer. Urol Int 63: 87-91, 1999.

30. Walther PJ: Interstitial brachytherapy for prostate cancer-just an expensive variant of 'watchful waiting'? Curr Opin Urol 9: 201-204, 1999.

31. D'Amico AV, Whittington R, Malkowicz SB, Fondurulia J, Chen MH, Kaplan I, Beard CJ, Tomaszewski JE, Renshaw AA, Wein A and Coleman CN: Pretreatment nomogram for prostatespecific antigen recurrence after radical prostatectomy or externalbeam radiation therapy for clinically localized prostate cancer. J Clin Oncol 17: 168-172, 1999.

32. Bertermann $\mathrm{H}$ and Brix F: Technik der perinealen interstitiellen Iridium-192-bestrahlung des Prostatakarzinoms. Verh Dtsch Ges Urol 38: 256-258, 1986.

33. Martinez AA, Kestin LL, Stromberg JS, Gonzalez JA, Wallace M, Gustafson GS, Edmundson GK, Spencer W and Vicini FA: Interim report of image-guided conformal high-dose-rate brachytherapy for patients with unfavorable prostate cancer: the William Beaumont phase II dose-escalating trial. Int J Radiat Oncol Biol Phys 47: 343-352 (R341/142), 2000.

34. Lee WR, deGuzman AF, Bare RL, Marshall MG and McCullough DL: Postimplant analysis of transperineal interstitial permanent prostate brachytherapy: evidence for a learning curve in the first year at a single institution. Int J Radiat Oncol Biol Phys 46: 83-88, 2000.

35. Damore SJ, Syed AM, Puthawala AA and Sharma A: Needle displacement during HDR brachytherapy in the treatment of prostate cancer. Int J Radiat Oncol Biol Phys 46: 1205-1211, 2000.

36. Lennernas B and Nilsson S: Calculated effects of displacement errors in external beam radiotherapy of prostatic adenocarcinoma. Acta Oncol 38: 203-208, 1999.

37. Debois M, Oyen R, Maes F, Verswijvel G, Gatti G, Bosmans H, Feron M, Bellon E, Kutcher G, van Poppel H and Vanuytsel L: The contribution of magnetic resonance imaging to the threedimensional treatment planning of localized prostate cancer. Int J Radiat Oncol Biol Phys 45: 857-865, 1999.

38. Dattoli M and Waller K: A simple method to stabilize the prostate during transperineal prostate brachytherapy. Int J Radiat Oncol Biol Phys 38: 341-342, 1997.

39. Pathak SD, Grimm PD, Chalana V and Kim Y: Pubic arch detection in transrectal ultrasound guided prostate cancer therapy. IEEE Trans Med Imaging 17: 762-771, 1998.

40. Loblaw DA, Wallner K, Dibiase S, Russell K, Blasko J and Ellis W: Brachytherapy in patients with small prostate glands. Tech Urol 6: 64-69, 2000.
41. Tincher SA, Kim RY, Ezekiel MP, Zinsli T, Fiveash JB, Raben DA, Bueschen AJ and Urban DA: Effects of pelvic rotation and needle angle on pubic arch interference during transperineal prostate implants. Int J Radiat Oncol Biol Phys 47 361-363, 2000.

42. Kalapurakal JA, Sathiaseelan V, Bista T and Marymont MH: Adverse impact of multileaf collimator field shaping on lens dose in children with acute leukemia receiving cranial irradiation. Int J Radiat Oncol Biol Phys 48: 1227-1231, 2000.

43. Porter AT, Blasko JC, Grimm PD, Reddy SM and Ragde H: Brachytherapy for prostate cancer. CA Cancer J Clin 45: 165-178, 1995.

44. Bolla M, Gonzalez D, Warde P, Dubois JB, Mirimanoff RO, Storme G, Bernier J, Kuten A, Sternberg C, Gil T, Collette L and Pierart M: Improved survival in patients with locally advanced prostate cancer treated with radiotherapy and goserelin. N Engl J Med 337: 295-300, 1997.

45. Blank KR, Whittington R, Arjomandy B, Wein AJ, Broderick G, Staley J and Malkowicz SB: Neoadjuvant androgen deprivation prior to transperineal prostate brachytherapy: smaller volumes, less morbidity. Cancer J Sci Am 5: 370-373, 1999.

46. Potters L, Torre T, Ashley R and Leibel S: Examining the role of neoadjuvant androgen deprivation in patients undergoing prostate brachytherapy. J Clin Oncol 18: 1187-1192 (R1181/ 1612), 2000

47. Bazinet M, Karakiewicz PI, Aprikian AG, Trudel C, Peloquin F, Dessureault J, Goyal M, Begin LR and Elhilali MM: Reassessment of non-planimetric transrectal ultrasound prostate volume estimates. Urology 47: 857-862, 1996.

48. Littrup PJ, Williams CR, Egglin TK and Kane RA: Determination of prostate volume with transrectal US for cancer screening. Part II. Accuracy of in vitro and in vivo techniques. Radiology 179: 49-53, 1991.

49. Martinez A, Galalae R, Gonzalez J, Mitchell C, Gustafson G and Kovacs G: No apparent benefit at 5 years from a course of neoadjuvant/concurrent androgen deprivation for patients with prostate cancer treated with a high total radiation dose. J Urol 170: 2296-2301, 2003.

50. Narayana V, Roberson PL, Pu AT, Sandler H, Winfield RH and McLaughlin PW: Impact of differences in ultrasound and computed tomography volumes on treatment planning of permanent prostate implants. Int J Radiat Oncol Biol Phys 37: 1181-1185, 1997.

51. Shirato H, Harada T, Harabayashi T, Hida K, Endo H, Kitamura K, Onimaru R, Yamazaki K, Kurauchi N, Shimizu T, Shinohara N, Matsushita M, Dosaka-Akita H and Miyasaka K: Feasibility of insertion/implantation of 2.0 -mm-diameter gold internal fiducial markers for precise setup and real-time tumour tracking in radiotherapy. Int J Radiat Oncol Biol Phys 56: 240247, 2003.

52. Sylvester J, Blasko JC, Grimm P and Ragde H: Interstitial implantation techniques in prostate cancer. J Surg Oncol 66: $65-75,1997$

53. Waterman FM and Dicker AP: Determination of the urethral dose in prostate brachytherapy when the urethra cannot be visualized in the postimplant CT scan. Med Phys 27: 448-451, 2000.

54. Dicker AP, Figura AT, Waterman FM, Valicenti RK, Strup SE and Gomella LG: Is there a role for antibiotic prophylaxis in transperineal interstitial permanent prostate brachytherapy? Tech Urol 6: 104-108, 2000.

55. Grann A and Wallner K: Prostate brachytherapy in patients with inflammatory bowel disease. Int J Radiat Oncol Biol Phys 40: 135-138, 1998.

56. Aggarwal S, Wallner K, True LD, Russell K, Sutlief S, Blasko J and Ellis W: Prostate brachytherapy in patients with prior evidence of prostatitis. Int J Radiat Oncol Biol Phys 45: 867-869, 1999.

57. Critz FA, Williams WH, Benton JB, Levinson AK, Holladay CT and Holladay DA: Prostate specific antigen bounce after radioactive seed implantation followed by external beam radiation for prostate cancer. J Urol 163: 1085-1089 (R1081/ 1779), 2000

58. Hanlon AL, Pinover WH, Horwitz EM and Hanks GE: Patterns and fate of PSA bouncing following 3D-CRT. Int J Radiat Oncol Biol Phys 50: 845-849, 2001.

59. Nickers P, Coppens L, Beauduin M, Sabatier J, Albert A, De Leval J and Deneufbourg JM: PSA kinetics after external beam radiotherapy alone or combined with an Iridium brachytherapy boost to deliver 85 grays to prostatic adenocarcinoma. Strahlenther Onkol 177: 90-95, 2001. 
60. Brenner DJ, Martinez AA, Edmundson GK, Mitchell C, Thames HD and Armour EP: Direct evidence that prostate tumours show high sensitivity to fractionation (low alpha/beta ratio), similar to late-responding normal tissue. Int J Radiat Oncol Biol Phys 52: 6-13, 2002.

61. Fowler J, Chappell R and Ritter M: Is alpha/beta for prostate tumours really low? Int J Radiat Oncol Biol Phys 50: 10211031, 2001

62. Fowler JF: The radiobiology of prostate cancer including new aspects of fractionated radiotherapy. Acta Oncol 44: 265-276, 2005.
63. Lai PP, Perez CA, Shapiro SJ and Lockett MA: Carcinoma of the prostate stage $B$ and $C$ : lack of influence of duration of radiotherapy on tumour control and treatment morbidity. Int $\mathrm{J}$ Radiat Oncol Biol Phys 19: 561-568, 1990.

64. Sanchez-Nieto B and Nahum AE: The delta-TCP concept: a clinically useful measure of tumour control probability. Int $\mathrm{J}$ Radiat Oncol Biol Phys 44: 369-380, 1999.

65. Ben-Josef E, Han S, Tobi M, Shaw LM, Bonner HS, Vargas BJ, Prokop S, Stamos B, Kelly L, Biggar S and Kaplan I: A pilot study of topical intrarectal application of amifostine for prevention of late radiation rectal injury. Int $\mathrm{J}$ Radiat Oncol Biol Phys 53: 1160-1164, 2002. 